
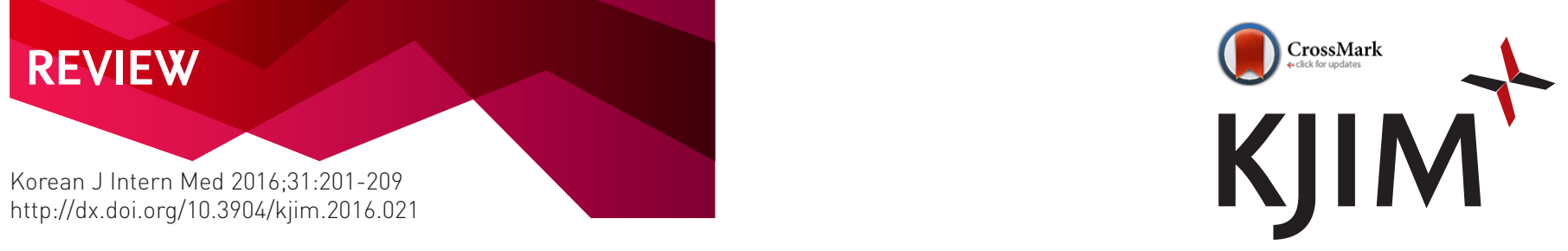

\title{
Diagnosis and management of gastric dysplasia
}

Jae Kyu Sung

Department of Internal Medicine, Chungnam National University School of Medicine, Daejeon, Korea

Received: February 1, 2016 Accepted: February 4, 2016

\section{Correspondence to}

Jae Kyu Sung, M.D.

Department of Internal Medicine, Chungnam National University School of Medicine, 282 Munhwa-ro, Jung-gu, Daejeon 35015 , Korea

Tel: $+82-42-280-7186$

Fax: +82-42-254-4553

E-mail:jksung69@cnuh.co.kr
Gastric dysplasia is a neoplastic lesion and a precursor of gastric cancer. The Padova, Vienna, and World Health Organization classifications were developed to overcome the discrepancies between Western and Japanese pathologic diagnoses and to provide a universally accepted classification of gastric epithelial neoplasia. At present, the natural history of gastric dysplasia is unclear. Much evidence suggests that patients with high-grade dysplasia are at high risk of progression to carcinoma or synchronous carcinoma. Therefore, endoscopic resection is required. Although patients with low-grade dysplasia have been reported to be at low risk of progression to carcinoma, due to the marked histologic discrepancies between forceps biopsy and endoscopic specimens, endoscopic resection for this lesion is recommended, particularly in the presence of other risk factors (large size; depressed gross type; surface erythema, unevenness, ulcer, or erosion; and tubulovillous or villous histology). Helicobacter pylori eradication in patients with dysplasia after endoscopic resection appear to reduce the incidence of metachronous lesions.

Keywords: Intraepithelial neoplasia; Dysplasia; Adenoma; Stomach

\section{INTRODUCTION}

Gastric cancer remains one of the most challenging malignant diseases worldwide. Gastric dysplasia is a precancerous lesion and the penultimate stage in gastric carcinogenesis, particularly the intestinal type, as hypothesized by Correa [1]. Therefore, identification, management, and surveillance of such lesions are important for early detection and prevention of gastric cancer. Nevertheless, the accurate diagnosis and management of this lesion remain controversial. Therefore, in this review, current knowledge of this lesion is discussed, together with relevant diagnostic and therapeutic strategies.

\section{DEFINITION}

The World Health Organization (WHO) defines dyspla- sia in the gastrointestinal system as the presence of histologically unequivocal neoplastic epithelium without evidence of tissue invasion [2]. Some confusion exists regarding the terms adenoma and dysplasia. Originally, adenoma was considered a raised circumscribed lesion, either sessile or pedunculated, in contrast to dysplasia, which was defined as a flat or depressed mucosa [3]. However, use of terms such as "flat adenoma" or "depressed adenoma" by some investigators has resulted in confusion. The WHO defines gastric adenomas as circumscribed, polypoid lesions composed of tubular and/ or villous structures, lined by dysplastic epithelium [4]. There has been an effort to standardize the terminology of adenoma and dysplasia; adenoma has been defined as neoplastic circumscribed benign lesions unassociated with underlying inflammation such as atrophic gastritis whether pedunculated, sessile, flat, or depressed. In contrast, dysplasia is defined as benign neoplastic lesions associated with underlying inflammation [5]. 
Currently, however, adenoma and dysplasia are used indiscriminately by most clinicians.

\section{CLASSIFICATION SYSTEMS}

Several dysplasia classification systems-including the Padova, Vienna, and WHO systems-have been developed to standardize the definition of gastric dysplasia and neoplasia between Western and Japanese pathologists (Table 1). This standardization was necessary because of the marked discrepancies between Western and Japanese pathologic diagnosis of these lesions. Carcinoma is diagnosed in Japan based on cytological and architectural changes irrespective of the presence of invasion, whereas in the Western system it is based on invasion into the lamina propria; this emphasizes invasion as an indicator of metastatic potential [6]. A weakness of the Japanese classification system is the lack of a distinction between noninvasive and invasive mucosal carcinoma; such a distinction seems to have prognostic importance. In contrast, the diagnostic discrepancies between biopsy specimens and corresponding resected specimens are a weakness of the Western classification system [6]. The Japanese Society for Research on Gastric Cancer classification does not include the term dysplasia. Dysplasia is usually classified as low or high grade. Low-grade dysplasia (LGD) and high-grade dysplasia (HGD) correspond to borderline lesions (group III) and strongly suspicious for invasive carcinoma (group IV), respectively, in this system [7]. In contrast, there is no recognition of noninvasive carcinoma and mucosal carcinoma without submucosal invasion in the Western system [7]. The Padova, Vienna, and WHO classification schemes aim to provide a universally accepted classification system for gastric epithelial neoplasia. On this basis, Japanese pathologists accepted use of the terms adenoma and dysplasia and Western pathologists accepted that of noninvasive carcinoma. LGD and HGD are classified as noninvasive, low-grade neoplasia of category 3 and noninvasive, high-grade neoplasia of category 4 in the Vienna and revised Vienna classification systems, respectively $[8,9]$. In this classification system, the diagnoses "carcinoma in situ," "suspicious for invasive carcinoma," and "intramucosal carcinoma" were included in category 4 [9]. The WHO classification is similar to the Vienna

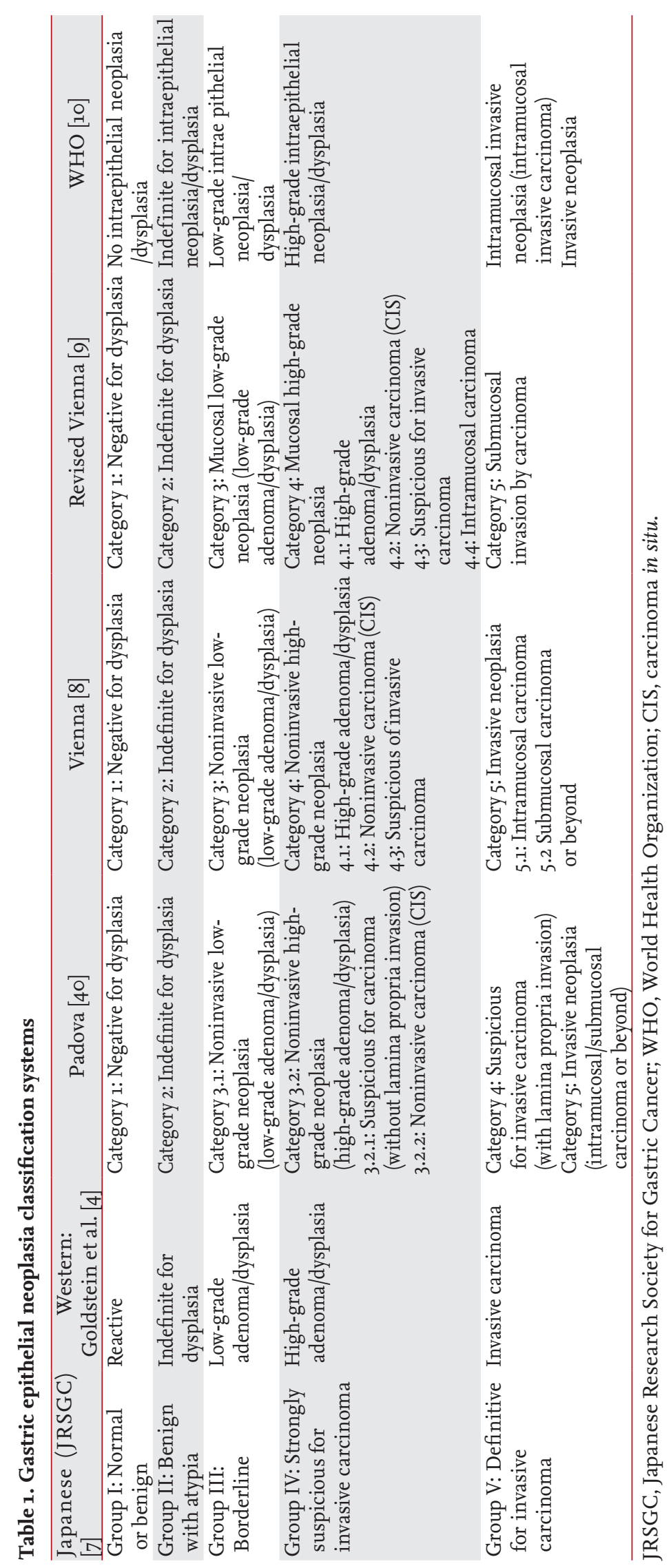


classification; however, the term "dysplasia" is used synonymously with "intraepithelial neoplasia/dysplasia" [10]. Therefore, categories 3 and 4 in the revised Vienna classification system correspond to low-grade and highgrade intraepithelial neoplasia/dysplasia, respectively, in the WHO classification.

\section{CLINICAL FEATURES AND NATURAL HISTORY}

The prevalence of dysplasia is reported to be $0.5 \%$ to $3.75 \%$ in Western countries and $9 \%$ to $20 \%$ in regions with a high incidence of gastric adenocarcinoma, such as Colombia and China [11]. Patients with such lesions are predominantly male and are $\sim 10$ years younger than gastric cancer patients (61.35 years for gastric dysplasia vs. 70 years for gastric cancer) [12]. Gastric dysplasia can be found anywhere in the stomach, but most commonly in the antrum [13]. Most gastric dysplasia is discovered incidentally during screening endoscopic examinations.

Both LGD and HGD have the potential to progress to carcinoma. Therefore, predicting the risk of malignant transformation at diagnosis for these lesions is important. However, the real risk of progression to cancer for dysplasia remains unclear. Indeed, well-defined, longterm follow-up studies, well-designed biopsy-sampling protocols, and obtaining informed patient consent can be problematic in clinical trials in terms of clarifying the natural history of gastric dysplasia. The risk of malignant change increases with the histological grade of the dysplasia. Previous studies have consistently demonstrated that patients with HGD are at high risk of progression to carcinoma or synchronous carcinoma. The rate of malignant change of HGD has been reported to be range from $60 \%$ to $85 \%$ over a median interval of 4 to 48 months [14-20]. A recent nationwide cohort study, which demonstrated that $25 \%$ of patients with HGD received a diagnosis of gastric cancer within 1 year of the initial diagnosis, confirmed the high risk of malignant change in HGD [21]. Compared to HGD, LGD has a lower risk of progression to carcinoma. LGD has been documented to regress in $38 \%$ to $75 \%$ and persist in $19 \%$ to $50 \%$ of cases [22]. Of LGD cases, $0 \%$ to $23 \%$ exhibit malignant change within a mean of 10 to 48 months $[15,18,20,23,24]$. Recent observational studies have confirmed the low risk of malignant change in patients with
LDG (3\% to 9\%) $[20,23]$.

Gastric dysplasia has a high risk of synchronous carcinoma in other areas of the stomach [25]. Synchronous adenocarcinoma has been found in up to $30 \%$ of patients with gastric dysplasia [26].

\section{HISTOLOGIC DISCREPANCY: FORCEPS BIOPSY AND ENDOSCOPIC RESECTION}

A concern regarding the accurate diagnosis of gastric dysplasia is that endoscopic forceps biopsy specimens are not representative of the entire lesion; therefore, significant discrepancies can be found between histologic diagnoses based on forceps biopsy and resected specimens (Fig. 1). A series of studies have reported that diagnosis of LGD by forceps biopsy could be upgraded to HGD or carcinoma. A recent meta-analysis [27] of 16 studies involving 3,303 patients with endoscopic forceps biopsy-proven gastric LGD lesions showed that $25 \%$ were diagnosed as advanced lesions, including gastric HGD (16.7\%) and gastric carcinoma (6.9\%) after endoscopic resection. In other words, one out of four forceps biopsy-proven gastric LGDs might be underdiagnosed and should actually be HGD or even gastric carcinoma. This high rate of underdiagnosis indicates that merely a follow-up strategy is insufficient for patients with LGD.

Repeat endoscopic biopsy is a possible solution to this issue. However, this also has limitations, as demonstrated by a $70.4 \%$ rate of histological concordance between repeat endoscopic biopsy and postendoscopic resection specimens [28].

Theoretically, obtaining a larger specimen using the large cup of jumbo biopsy forceps (open diameter of 8 $\mathrm{mm}$ ) can increase diagnostic accuracy. However, a recent study reported that jumbo forceps biopsy specimens do not increase the concordance rate compared to conventional forceps (open diameter of $6.8 \mathrm{~mm}$ ) specimens [29]. The authors instead recommended obtaining at least four endoscopic biopsy specimens to improve the histologic accuracy. This resulted in an increased concordance rate in LGD from $76.2 \%$ for the first endoscopic biopsy to $95.2 \%$ [29]. However, increasing the number or size of forceps biopsies can alter the neoplastic lesion and cause submucosal fibrosis, which can make endoscopic resection problematic. Therefore, these strate- 

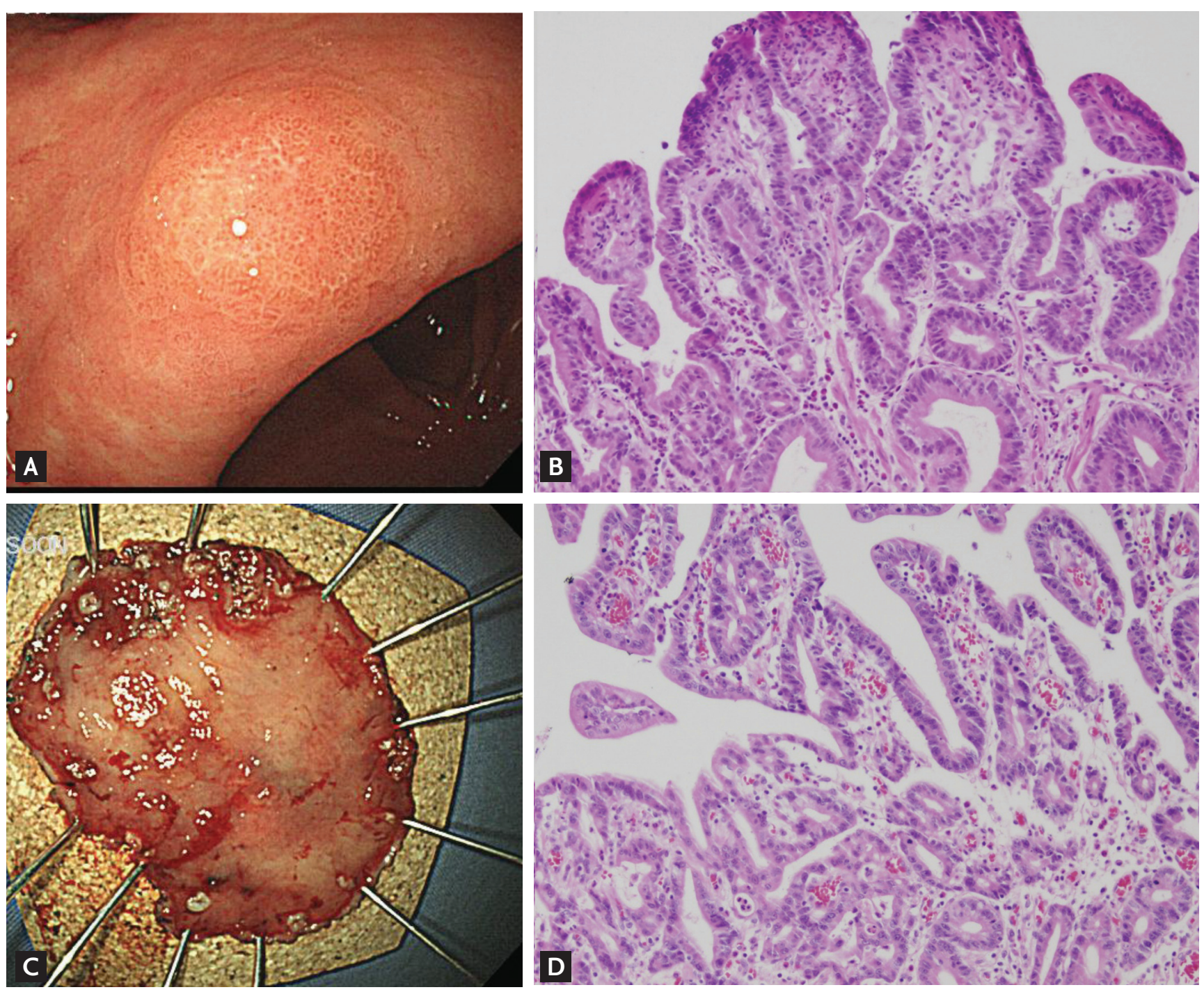

Figure 1. A lesion whose diagnosis was upgraded from gastric low-grade dysplasia to early gastric cancer after endoscopic resection. (A) Endoscopic findings before endoscopic resection show a $0.6 \times 0.5 \mathrm{~cm}$ superficial elevated mass at the lesser curvature of the antrum. (B) Histologic features of low-grade dysplasia in the initial forceps biopsy specimen (H\&E, $\times 200)$. (C) The endoscopic submucosal dissection specimen $(3.7 \times 2.7 \mathrm{~cm})$. (D) Histologic features of the resected specimen. Moderately differentiated tubular adenocarcinoma arising from a tubular adenoma is evident. The tumor was $0.5 \times 0.4 \mathrm{~cm}$ in size $(\mathrm{H} \& \mathrm{E}, \times 200)$.

gies to improve diagnostic accuracy have limitations in terms of clinical application.

It is important to determine the type of gastric LGD likely to be underdiagnosed. Various findings have been reported concerning this issue. It is generally accepted that the probability of malignant transformation of dysplasia increases with lesion size. Adenoma $2 \mathrm{~cm}$ or more in diameter has been considered potentially malignant [30]. Several studies have confirmed that a lesion size $\geq$ $2 \mathrm{~cm}$ is an independent predictor of upgraded histology in LGD lesions. However, even small LGDs (<2 cm) may be upgraded to an HGD or carcinoma. One study indicated that $\sim 20 \%$ of lesions with a diameter of less than 1 $\mathrm{cm}$ and about $35 \%$ of those with a diameter of 1 to $1.9 \mathrm{~cm}$ were HGD or carcinoma [31]. Other studies showed that forceps biopsy-proven gastric LGDs of $\geq 1 \mathrm{~cm}$ diameter were an independent risk factor for HGD or carcinoma [32,33].

The surface appearance of dysplasia has also been identified as a risk factor for upgrade to a diagnosis of HGD or carcinoma in gastric LGD after endoscopic resection. Features associated with an upgraded diagnosis 
include depressed macroscopic type, surface erythema, surface unevenness (nodularity), and erosion or ulceration [31,32,34-39]. The risk of malignancy is also related to the villosity of the growth pattern [33].

In summary, larger size; depressed gross type; a surface appearance with erythema, unevenness, ulcer, or erosion; and tubulovillous or villous histology on forceps biopsy specimens are predictive factors for an upgraded diagnosis in LGD patients following endoscopic resection. Therefore, it is recommended that an endoscopic forceps biopsy-proven gastric LGD lesion with these predictive factors undergo endoscopic resection.

\section{MANAGEMENT}

Generally there is no controversy regarding the appropriate management of HGD. Such lesions require endoscopic resection due to the potential for progression to carcinoma and the coexistence of carcinoma. In contrast, few definite guidelines regarding the management of LGD are available. Given the lower risk of malignant transformation, some investigators recommend annual endoscopic surveillance with rebiopsy for LGD $[40,41]$, while others suggest that active resection is necessary because histological diagnosis based on forceps biopsy can be inaccurate due to sampling error, and the final diagnosis can be upgraded to HGD or even invasive carcinoma after endoscopic resection [42]. Repeated endoscopic examination with biopsies can impose a physical, psychological, and financial burden on the patient, although few studies of these issues have been reported [42]. In contrast, endoscopic resection is less invasive than surgical resection but also has a risk of complications.

In the revised Vienna classification, endoscopic treatment or surgical local treatment was recommended for HGD [43]. In addition, endoscopic treatment or follow-up was recommended for LGD [43]. The choice of treatment is dependent on the size of the lesion; depth of invasion as assessed endoscopically, radiologically, or ultrasonographically; and other general factors (patient age and comorbidities) [43].

Several guidelines recommend endoscopic resection for gastric dysplasia. The most recent American Society for Gastrointestinal Endoscopy (ASGE) guidelines
[44] suggested that adenoma of any size should be removed endoscopically if possible. The British Society of Gastroenterology guidelines [13] also recommended complete removal of adenoma if safe to do so. The European guidelines [45] recommended that if LGD is diagnosed endoscopically, endoscopic resection should be considered to obtain a more accurate histologic diagnosis. Otherwise, endoscopically indefinite lesions should undergo follow-up within 1 year after diagnosis. In addition, they recommended that endoscopic resection should be considered for patients with endoscopically defined HGD. If the lesion is endoscopically indistinct HGD, the guidelines recommend immediate endoscopic reassessment with extensive biopsy sampling and surveillance at 6- to 12-month intervals. Moreover, they highlighted that disappearance of dysplasia or its assumed disappearance as assessed by follow-up endoscopic biopsies does not rule out the possible progression to invasive cancer.

Finally, because there is a risk of synchronous carcinoma in patients with gastric dysplasia, thorough evaluation of the entire stomach should be performed and any abnormalities biopsied. Endoscopic surveillance is also mandatory after resection to screen for metachronous lesions $[13,46]$. Concerning the surveillance schedule, the ASGE guidelines suggest surveillance endoscopy 1 year following resection of gastric dysplasia [44]. The British Society of Gastroenterology guidelines recommend endoscopic follow-up 6 months after resection in patients with incompletely resected polyps or those with HGD, and 1 year after removal of other polyps [13].

\section{HELICOBACTER PYLORI ERADICATION FOR PREVENTION OF METACHRONOUS LESIONS AFTER ENDOSCOPIC RESECTION OF GASTRIC DYSPLASIA}

Previous studies have evaluated the effect of Helicobacter pylori eradication on preneoplastic lesions such as gastric atrophy and intestinal metaplasia. Conflicting results have been reported regarding the reversibility of gastric atrophy and intestinal metaplasia after eradication therapy. H. pylori eradication appears to improve atrophy but not intestinal metaplasia [47]. Another issue is whether $H$. pylori eradication reduces the subsequent 
development of metachronous cancer after endoscopic resection of early gastric cancer (EGC). Nonrandomized and randomized control studies have demonstrated that $H$. pylori eradication can reduce the development of metachronous gastric cancer after endoscopic resection of EGC $[48,49]$. Based on these results, several guidelines recommend $H$. pylori eradication in patients with previous EGC after endoscopic resection [50-54].

Few studies have assessed the effect of $H$. pylori eradication on gastric dysplasia. Studies regarding the effect of $\mathrm{H}$. pylori eradication on the development of metachronous lesion after endoscopic resection of gastric dysplasia are also limited [55-58]. Correa et al. [55] demonstrated that $H$. pylori eradication and dietary supplementation increased the rate of regression of precancerous lesions, including dysplasia. However, that study had several limitations, such as a small number of patients and issues with diagnosis of dysplasia; that is, the majority of subjects with dysplasia should have been classified as "indefinite for dysplasia" according to international standards. A long-term follow-up (> 12 months) study showed that $H$. pylori eradication significantly altered the natural history of advanced precancerous changes [58]. A significantly lower risk of evolution into highgrade noninvasive neoplasia or into invasive gastric cancer was found in patients with $\mathrm{H}$. pylori-eradicated lowgrade noninvasive neoplasia compared to those with $H$. pylori-positive low-grade noninvasive neoplasia. To date, the preponderance of evidence suggests that eradication has no effect on dysplasia.

However, some studies have demonstrated that $H$. pylori eradication can prevent the development of metachronous lesions after endoscopic resection of gastric dysplasia. In one retrospective study of 1872 patients with gastric dysplasia who underwent endoscopic resection, the cumulative incidence of metachronous lesions was significantly lower in the $H$. pylori-eradicated group than the $\mathrm{H}$. pylori-persistent (noneradicated or failed) group [59]. Another retrospective study analyzed 1,007 patients with EGC who underwent endoscopic resection, and found that $H$. pylori eradication reduced the metachronous recurrence of gastric neoplasm [6o]. Furthermore, this outcome remained evident in an analysis that included 480 patients with LGD [6o]. Another retrospective study that assessed 129 patients positive for $H$. pylori who underwent endoscopic resection for gastric dysplasia [61] found that $H$. pylori eradication was an independent risk factor for a reduced incidence of subsequent gastric dysplasia. Therefore, $H$. pylori eradication may be useful for the prevention of metachronous lesions after endoscopic resection in patients with gastric dysplasia.

Currently, the European guidelines recommend $H$. pylori eradication for patients with previous dysplasia after endoscopic or surgical therapy [45]. The ASGE guidelines also recommend $H$. pylori eradication in patients with dysplasia. In addition, they recommend systemic sampling of the surrounding nonpolypoid gastric mucosa to evaluate H. pylori and metaplastic atropic gastritis in the presence of multiple dysplasias [44].

\section{CONCLUSIONS}

Accurate diagnosis, management, and surveillance of gastric dysplasia are critical for early detection and prevention of gastric cancer. Due to the significant diagnostic discrepancies between forceps biopsy and endoscopic resected specimens, endoscopic resection should be considered not only for diagnosis but also treatment of gastric dysplasia. Fig. 2 shows a proposed treatment strategy for gastric intraepithelial dysplasia diagnosed by endoscopic biopsy. Endoscopic surveillance is essential and $H$. pylori eradication may be beneficial for prevention of metachronous lesions after endoscopic resec-

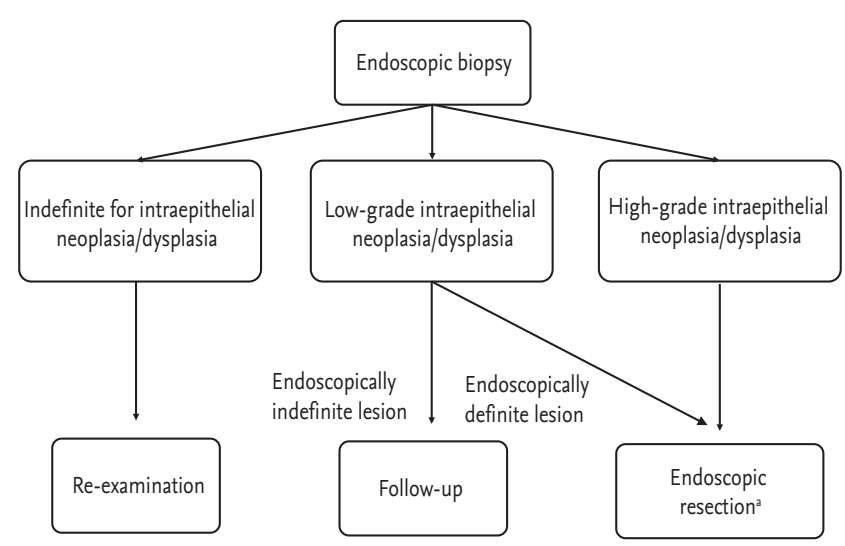

Figure 2. Proposal of treatment strategy for gastric intraepithelial neoplasia/dysplasia diagnosed by endoscopic biopsy. ${ }^{a}$ Helicobacter pylori eradication is recommended if identified after endoscopic resection in patients with dysplasia. 
tion in patients with gastric dysplasia.

\section{Conflict of interest}

No potential conflict of interest relevant to this article was reported.

\section{REFERENCES}

1. Correa P. A human model of gastric carcinogenesis. Cancer Res 1988;48:3554-3560.

2. Morson BC, Sobin LH, Grundmann E, Johansen A, Nagayo T, Serck-Hanssen A. Precancerous conditions and epithelial dysplasia in the stomach. J Clin Pathol 1980;33:711-721.

3. Ming SC. Dysplasia of gastric epithelium. Front Gastrointest Res 1979;4:164-172.

4. Goldstein NS, Lewin KJ. Gastric epithelial dysplasia and adenoma: historical review and histological criteria for grading. Hum Pathol 1997;28:127-133.

5. Lewin KJ. Nomenclature problems of gastrointestinal epithelial neoplasia. Am J Surg Pathol 1998;22:1043-1047.

6. Schlemper RJ, Kato Y, Stolte M. Review of histological classifications of gastrointestinal epithelial neoplasia: differences in diagnosis of early carcinomas between Japanese and Western pathologists. J Gastroenterol 2001;36:445-456.

7. Schlemper RJ, Itabashi M, Kato Y, et al. Differences in diagnostic criteria for gastric carcinoma between Japanese and western pathologists. Lancet 1997;349:1725-1729.

8. Schlemper RJ, Riddell RH, Kato Y, et al. The Vienna classification of gastrointestinal epithelial neoplasia. Gut 2000;47:251-255.

9. Schlemper RJ, Kato Y, Stolte M. Diagnostic criteria for gastrointestinal carcinomas in Japan and Western countries: proposal for a new classification system of gastrointestinal epithelial neoplasia. J Gastroenterol Hepatol 2000;15 Suppl:G49-G57.

10. Yakirevich E, Resnick MB. Pathology of gastric cancer and its precursor lesions. Gastroenterol Clin North Am 2013;42:261-284.

11. Lauwers GY, Riddell RH. Gastric epithelial dysplasia. Gut 1999;45:784-790.

12. Setia N, Lauwers GY. Gastric dysplasia: update and practical approach. Diagn Histopathol 2015;21:312-322.

13. Goddard AF, Badreldin R, Pritchard DM, Walker MM,
Warren B; British Society of Gastroenterology. The management of gastric polyps. Gut 2010;59:1270-1276.

14. Lansdown M, Quirke P, Dixon MF, Axon AT, Johnston D. High grade dysplasia of the gastric mucosa: a marker for gastric carcinoma. Gut 1990;31:977-983.

15. Di Gregorio C, Morandi P, Fante R, De Gaetani C. Gastric dysplasia: a follow-up study. Am J Gastroenterol 1993;88:1714-1719.

16. Rugge M, Farinati F, Di Mario F, Baffa R, Valiante F, Cardin F. Gastric epithelial dysplasia: a prospective multicenter follow-up study from the Interdisciplinary Group on Gastric Epithelial Dysplasia. Hum Pathol 1991;22:10021008.

17. Saraga EP, Gardiol D, Costa J. Gastric dysplasia: a histological follow-up study. Am J Surg Pathol 1987;11:788-796.

18. Fertitta AM, Comin U, Terruzzi V, et al. Clinical significance of gastric dysplasia: a multicenter follow-up study: Gastrointestinal Endoscopic Pathology Study Group. Endoscopy 1993;25:265-268.

19. Kokkola A, Haapiainen R, Laxen F, et al. Risk of gastric carcinoma in patients with mucosal dysplasia associated with atrophic gastritis: a follow up study. J Clin Pathol 1996;49:979-984.

20. Yamada H, Ikegami M, Shimoda T, Takagi N, Maruyama M. Long-term follow-up study of gastric adenoma/dysplasia. Endoscopy 2004;36:390-396.

21. de Vries AC, van Grieken NC, Looman CW, et al. Gastric cancer risk in patients with premalignant gastric lesions: a nationwide cohort study in the Netherlands. Gastroenterology 2008;134:945-952.

22. Srivastava A, Lauwers GY. Gastric epithelial dysplasia: the Western perspective. Dig Liver Dis 2008;40:641-649.

23. Rugge M, Cassaro M, Di Mario F, et al. The long term outcome of gastric non-invasive neoplasia. Gut 2003;52:11111116.

24. Park SY, Jeon SW, Jung MK, et al. Long-term follow-up study of gastric intraepithelial neoplasias: progression from low-grade dysplasia to invasive carcinoma. Eur J Gastroenterol Hepatol 2008;20:966-970.

25. Carmack SW, Genta RM, Graham DY, Lauwers GY. Management of gastric polyps: a pathology-based guide for gastroenterologists. Nat Rev Gastroenterol Hepatol 2009;6:331-341.

26. Abraham SC, Park SJ, Lee JH, Mugartegui L, Wu TT. Genetic alterations in gastric adenomas of intestinal and foveolar phenotypes. Mod Pathol 2003;16:786-795. 
27. Zhao G, Xue M, Hu Y, Lai S, Chen S, Wang L. How commonly is the diagnosis of gastric low grade dysplasia upgraded following endoscopic resection? A meta-analysis. PLoS One 2015;10:e0132699.

28. Nam KW, Song KS, Lee HY, et al. Spectrum of final pathological diagnosis of gastric adenoma after endoscopic resection. World J Gastroenterol 2011;17:5177-5183.

29. Jeon HK, Ryu HY, Cho MY, et al. A randomized trial to determine the diagnostic accuracy of conventional vs. jumbo forceps biopsy of gastric epithelial neoplasias before endoscopic submucosal dissection: open-label study. Gastric Cancer 2014;17:661-668.

30. Tomasulo J. Gastric polyps. Histologic types and their relationship to gastric carcinoma. Cancer 1971;27:1346-1355.

31. Cho SJ, Choi IJ, Kim CG, et al. Risk of high-grade dysplasia or carcinoma in gastric biopsy-proven low-grade dysplasia: an analysis using the Vienna classification. Endoscopy 2011;43:465-471.

32. Choi CW, Kim HW, Shin DH, et al. The risk factors for discrepancy after endoscopic submucosal dissection of gastric category 3 lesion (low grade dysplasia). Dig Dis Sci 2014;59:421-427.

33. Min BH, Kim KM, Kim ER, et al. Endoscopic and histopathological characteristics suggesting the presence of gastric mucosal high grade neoplasia foci in cases initially diagnosed as gastric mucosal low grade neoplasia by forceps biopsy in Korea. J Gastroenterol 2011;46:17-24.

34. Kim MK, Jang JY, Kim JW, et al. Is lesion size an independent indication for endoscopic resection of biopsy-proven low-grade gastric dysplasia? Dig Dis Sci 2014;59:428435 .

35. Lim H, Jung HY, Park YS, et al. Discrepancy between endoscopic forceps biopsy and endoscopic resection in gastric epithelial neoplasia. Surg Endosc 2014;28:1256-1262.

36. Won CS, Cho MY, Kim HS, et al. Upgrade of lesions initially diagnosed as low-grade gastric dysplasia upon forceps biopsy following endoscopic resection. Gut Liver 2011;5:187-193.

37. Lee CK, Chung IK, Lee SH, et al. Is endoscopic forceps biopsy enough for a definitive diagnosis of gastric epithelial neoplasia? J Gastroenterol Hepatol 2010;25:1507-1513.

38. Park DI, Rhee PL, Kim JE, et al. Risk factors suggesting malignant transformation of gastric adenoma: univariate and multivariate analysis. Endoscopy 2001;33:501-506.

39. Kim JH, Kim YJ, An J, et al. Endoscopic features suggesting gastric cancer in biopsy-proven gastric adeno- ma with high-grade neoplasia. World J Gastroenterol 2014;20:12233-12240.

40. Rugge M, Nitti D, Farinati F, di Mario F, Genta RM. Non-invasive neoplasia of the stomach. Eur J Gastroenterol Hepatol 2005;17:1191-1196.

41. Weinstein WM, Goldstein NS. Gastric dysplasia and its management. Gastroenterology 1994;107:1543-1545.

42. Nishida T, Tsutsui S, Kato M, et al. Treatment strategy for gastric non-invasive intraepithelial neoplasia diagnosed by endoscopic biopsy. World J Gastrointest Pathophysiol 2011;2:93-99.

43. Dixon MF. Gastrointestinal epithelial neoplasia: Vienna revisited. Gut 2002;51:130-131.

44. ASGE Standards of Practice Committee, Evans JA, Chandrasekhara $\mathrm{V}$, et al. The role of endoscopy in the management of premalignant and malignant conditions of the stomach. Gastrointest Endosc 2015;82:1-8.

45. Dinis-Ribeiro M, Areia M, de Vries AC, et al. Management of precancerous conditions and lesions in the stomach (MAPS): guideline from the European Society of Gastrointestinal Endoscopy (ESGE), European Helicobacter Study Group (EHSG), European Society of Pathology (ESP), and the Sociedade Portuguesa de Endoscopia Digestiva (SPED). Endoscopy 2012;44:74-94.

46. Jang MY, Cho JW, Oh WG, et al. Clinicopathological characteristics of synchronous and metachronous gastric neoplasms after endoscopic submucosal dissection. Korean J Intern Med 2013;28:687-693.

47. Choi IJ. Current evidence of effects of Helicobacter pylori eradication on prevention of gastric cancer. Korean J Intern Med 2013;28:525-537.

48. Uemura N, Mukai T, Okamoto S, et al. Effect of Helicobacter pylori eradication on subsequent development of cancer after endoscopic resection of early gastric cancer. Cancer Epidemiol Biomarkers Prev 1997;6:639-642.

49. Fukase K, Kato M, Kikuchi S, et al. Effect of eradication of Helicobacter pylori on incidence of metachronous gastric carcinoma after endoscopic resection of early gastric cancer: an open-label, randomised controlled trial. Lancet 2008;372:392-397.

50. Chey WD, Wong BC; Practice Parameters Committee of the American College of Gastroenterology. American College of Gastroenterology guideline on the management of Helicobacter pylori infection. Am J Gastroenterol 2007;102:1808-1825.

51. Malfertheiner P, Megraud F, O'Morain CA, et al. Manage- 
ment of Helicobacter pylori infection: the Maastricht IV/ Florence Consensus Report. Gut 2012;61:646-664.

52. Asaka M, Kato M, Takahashi S, et al. Guidelines for the management of Helicobacter pylori infection in Japan: 2009 revised edition. Helicobacter 2010;15:1-20.

53. Fock KM, Katelaris P, Sugano K, et al. Second Asia-Pacific Consensus Guidelines for Helicobacter pylori infection. J Gastroenterol Hepatol 2009;24:1587-1600.

54. Kim SG, Jung HK, Lee HL, et al. Guidelines for the diagnosis and treatment of Helicobacter pylori infection in Korea, 2013 revised edition. Korean J Gastroenterol 2013;62:3-26.

55. Correa P, Fontham ET, Bravo JC, et al. Chemoprevention of gastric dysplasia: randomized trial of antioxidant supplements and anti-helicobacter pylori therapy. J Natl Cancer Inst 2000;92:1881-1888.

56. Mera R, Fontham ET, Bravo LE, et al. Long term follow up of patients treated for Helicobacter pylori infection. Gut 2005;54:1536-1540.
57. You WC, Brown LM, Zhang L, et al. Randomized double-blind factorial trial of three treatments to reduce the prevalence of precancerous gastric lesions. J Natl Cancer Inst 2006;98:974-983.

58. Rugge M, Russo VM, Guido M. Review article: what have we learnt from gastric biopsy? Aliment Pharmacol Ther 2003;17 Suppl 2:68-74.

59. Shin SH, Jung da H, Kim JH, et al. Helicobacter pylori eradication prevents metachronous gastric neoplasms after endoscopic resection of gastric dysplasia. PLoS One 2015;10:e0143257.

60. Bae SE, Jung HY, Kang J, et al. Effect of Helicobacter pylori eradication on metachronous recurrence after endoscopic resection of gastric neoplasm. Am J Gastroenterol 2014;109:60-67.

61. Chon I, Choi C, Shin CM, Park YS, Kim N, Lee DH. Effect of Helicobacter pylori eradication on subsequent dysplasia development after endoscopic resection of gastric dysplasia. Korean J Gastroenterol 2013;61:307-312. 